\title{
PHENOL removal in refinery wastewater using mixed oxides prepared by green synthesis
}

\section{DOI : 10.36909/jer.13917}

Fatai Alade Aderibigbe*, Tunmise Latifat Adewoye*, Sherif Ishola Mustapha*, Ishaq Alhassan Mohammed*, Harvis Bamidele Saka**, Mutiu Kolade Amosa***, Ayoade Lateef Adejumo****, Rasheed Uthman Owolabi*****, and Shalom Boluwatife James*

*Department of Chemical Engineering, Faculty of Engineering and Technology, University of Ilorin, Ilorin, Nigeria

**Quality Control Department, Segmax Oil Nigeria Limited, Kere-Aje, Ogbondoroko, Kwara State, Nigeria

***Waste Management Unit, HSE Division, Department of Petroleum Resources, 7, Sylvester Ugoh Crescent, Jabi, Abuja-FCT, Nigeria.

***National Improved Oil Recovery Centre, NOGEC Complex, 7, Kofo Abayomi Street, Victoria Island, Lagos, Nigeria.

****Department of Chemical Engineering, Osun State University, Osogbo, Nigeria *****Department of Chemical Engineering, University of Lagos, Lagos, Nigeria

*Email: aderibigbe.fa@unilorin.edu.ng; Corresponding Author.

\begin{abstract}
Mixed solid oxides are known for their excellent catalytic property and applications in environmental remediation. This study presents a green-synthesis route for magnesium oxidetitanium oxide, a mixed oxide here demonstrated to possess high performance of phenol removal from hydrocarbon refinery process wastewater. Mixed oxide $\left(\mathrm{MgO}-\mathrm{TiO}_{2}\right)$ was prepared by using the whole extract from leaves of Piliostigma Thonningii as reducing agent. A structural attribute of the mixed oxide was investigated using X-ray Diffractometer, HighResolution Scanning Electronic Microscopy and Energy Dispersive X-ray. Petroleum refinery raw wastewater having phenol concentration of $19.961 \mathrm{mg} / \mathrm{L}$ was treated using the greensynthesized mixed oxide. Adsorptive phenols removal up to $99.5 \%$ was achieved with a dosage of $0.04 \mathrm{~g} / 100 \mathrm{~mL}$ at temperature of $35^{\circ} \mathrm{C}$, and contact time of $1.167 \mathrm{~h}$. By this, the treated water meets the standard acceptable phenol concentration $(0.1 \mathrm{mg} / \mathrm{L})$ in wastewater of hydrocarbon refinery.
\end{abstract}


Keywords: green synthesis; magnesium oxide; mixed oxide; phenol; process wastewater; titanium oxide.

\section{INTRODUCTION}

The environmental problem caused by organic pollutants especially the phenolic compounds, and their contributions to water pollution has been widely reported in the literature (Vasudevan, 2014: Gupta \& Balomajumder, 2015). It has been estimated that globally, over one billion people do not have access to safe drinking water, meanwhile, pollutants majorly due to industrialization have continually contaminated the available water sources through the introduction of such substances (such as phenol) into the water bodies (Jinxia et al., 2019; Mais et al., 2019).

Phenolic compounds have generally been found to be one of the most dangerous organic pollutants in wastewater from the refinery. A very low amount of phenolic compounds in water still makes it extremely toxic for human consumption (Mohamadi et al., 2015). In natural waters, the presence of phenol allows the formation of other toxic compounds through oxidation processes. In addition, the several methods used for the removal of phenols from wastewater have been observed to be confined because they often involve high capital and operational costs. Such existing methods include electrocoagulation, extraction, volatilization, hot gas or steam stripping, ion exchange, microbial degradation, membrane separation, solvent extraction, polymerization and many others (Tasic \& Antonijevic, 2014).

Popular methods of phenol degradation that have continually gained interest are the adsorption technique and photocatalysis. Energy-saving and the vast opportunity to develop efficient adsorbents and photocatalytic semiconducting materials from abundant and cheap materials are major motivating factors that have favoured the interest in the two methods. Particularly, mixed solid oxides such as $\mathrm{MgO}-\mathrm{SiO}_{2}, \mathrm{Al}_{2} \mathrm{O}_{3}-\mathrm{SiO}_{2}, \mathrm{TiO}_{2}-\mathrm{SiO}_{2}$, and $\mathrm{ZrO}_{2}-\mathrm{SiO}_{2}$ systems have long been studied due to their excellent catalytic activity resulting from the acid or basic 
properties (Itoh et al., 1974). In recent times, the development of mixed metal oxides as adsorbents for wastewater treatment has attracted the attention of researchers due to their synergistic effect and enhanced adsorption capability (Chen et al., 2018).

More recently, Khan et al. (2021) employed (Fe-Mg) binary metal oxide in removing arsenic from contaminated water. The adsorbent showed promising results in terms of high arsenic uptake. In another study, Mustapha et al. (2021) prepared silver and titanium oxidesdoped activated carbon as adsorbents for the removal of phenols from pharmaceutical wastewater. The reducing activity of whole extracts of Shea butter leaves on the nitrate salts of silver and titanium was illustrated towards the preparation of silver and titanium oxides, and an activated carbon doped with the oxides was found suitable for adsorptive removal of total phenols from pharmaceutical wastewater. Due to its environmentally benign principles and the potential to produce novel bespoke materials, green synthesis has proved to be one of the best synthesis processes for synthesizing metal oxide nanoparticles.

In the present study, the green synthesis method was utilized to develop a mixed oxide of $\mathrm{MgO}-\mathrm{TiO}_{2}$ using leaves extract of Piliostigma thonningii and applied in an adsorption process (non-photocatalytic) towards the removal of phenol from process water sourced from petroleum refinery

\section{METHODOLOGY}

\section{Materials}

Process wastewater was obtained from an indigenous Petroleum Refining and Petrochemical Company in Nigeria. Analytical grade magnesium nitrate hexahydrate (99\%, Sigma Aldrich) and titanium nitrate tetrahydrate (99.9\%, Sigma Aldrich) were used. Camel's foot leaf (Piliostigma Thonningii) was gotten from Ilorin, Nigeria. The leaves were sun-dried for 3 days, chopped into small pieces and then mortar and pestle were used to reduce it to powdery form. Dried powdered camel's foot leaves $(4 \mathrm{~g})$ was introduced into the conical flask containing 
$100 \mathrm{~mL}$ of distilled water. It was magnetically stirred (MS-H280-Pro digital magnetic hotplate stirrer) at $80^{\circ} \mathrm{C}$ for $50 \mathrm{~min}$. Filtration of the extract yielded the filtrate that was used in the preparation of mixed oxide. Fourier transform infrared spectrum of the extract from Piliostigma Thonningii was acquired using a Bruker Vertex 70 spectrometer (Bruker Optics, Billerica, MA, USA) to identify the presence of functional groups. Also, phenolic content in the refinery process water was estimated using Folin-Ciocalteu method (Folin, 1927).

\section{Mixed oxide preparation and characterization}

In a $400 \mathrm{~mL}$ conical flask, $5.75 \mathrm{~g}$ of titanium nitrate was dissolved in distilled water (15.63 $\mathrm{mL}$ ) and stirred for $2 \mathrm{~h}$ to obtain $1 \mathrm{M}$ aqueous solution. In another flask, $15.9 \mathrm{~g}$ of magnesium nitrate was dissolved in distilled water $(62 \mathrm{~mL})$ and agitated for $2 \mathrm{~h}$ to obtain $1 \mathrm{M}$ aqueous solution. The two solutions were mixed, and $7.76 \mathrm{~mL}$ of leaf extract was added. It was centrifuged at $4000 \mathrm{rpm}$ for $4 \mathrm{~h}$ and filtered. The filtrate was dried at $90{ }^{\circ} \mathrm{C}$ for $2 \mathrm{~h}$ and calcined at $500{ }^{\circ} \mathrm{C}$ for $3 \mathrm{~h}$. Mixed oxide $\mathrm{MgO}-\mathrm{TiO}_{2}$ was then stored in a sample bottle until use. Structural characterization of the mixed oxide was carried out using X-ray diffraction (Bruker AXS D8 Advance, USA), high resolution scanning electron microscopy and Energy-dispersive X-ray spectroscopy (Zeiss Auriga, USA). The XRD pattern was acquired at room temperature $\left(25^{\circ} \mathrm{C}\right)$ with $\mathrm{Cu} \mathrm{K} \alpha$ radiation $(\lambda=1.5406 \mathrm{~m})$. The spectra ranged from 15 to $80^{\circ}$ at a step of $0.034^{\circ}$.

\section{Phenol degradation using mixed oxide $\mathrm{MgO}-\mathrm{TiO}_{2}$}

Batch adsorption experiments were carried out using Mixed Oxide $\left(\mathrm{MgO}-\mathrm{TiO}_{2}\right)$ to study the percentage phenol removal. Adsorption conditions were varied for adsorbent dosage, contact time, and temperature as shown in Table 1. 
Table 1 Batch adsorption parameters

Variable $\quad$ Dosage $(\mathrm{g}) \quad$ Contact time $(\mathrm{min}) \quad$ Temperature $\left({ }^{\circ} \mathrm{C}\right)$

\begin{tabular}{llll}
\hline$(+)$ & 0.1 & 80 & 50 \\
$(-)$ & 0.02 & 10 & 35
\end{tabular}

In a typical experiment, a measured quantity of the mixed oxide $(0.02 \mathrm{~g})$ was added to $50 \mathrm{~mL}$ of the refinery wastewater, followed by shaking of the mixture in an orbital shaker at the desired temperature for a given period. Total phenol removal and the adsorption capacity were obtained from Equations (1) and (2) respectively;

$\%$ Removal $=\left(C_{0}-C_{e}\right) \times 100 / C_{0}$.

The terms, $\mathrm{C}_{\mathrm{o}}$ and $\mathrm{C}_{\mathrm{e}}$ are the initial concentration $(\mathrm{mg} / \mathrm{L})$, and the final concentration of phenol at equilibrium $(\mathrm{mg} / \mathrm{L})$ respectively.

$$
q_{e}=\frac{\left(C_{o}-C_{e}\right) V}{W}
$$

Symbols represents, adsorption capacity $\left(q_{e}\right)$, the volume of solution $(V(L)$, and the mass of adsorbent $(W(g)$. Three kinetic models were used to examine the experimental data acquired from the adsorption process to describe the mechanism controlling the adsorption process. These are presented in Equations (3) - (5) respectively for pseudo-first order, pseudo-second order, and intra-particle diffusion models;

$$
\begin{aligned}
& \log \left(q_{e}-q_{t}\right)=\log q_{e}-k_{1} t / 2.303 \\
& \frac{t}{q_{t}}=\frac{1}{k_{2} q_{e}}+\frac{t}{q_{e}} \\
& q_{t}=k_{p} t^{\frac{1}{2}}+C
\end{aligned}
$$

Quantity of phenol adsorbed at time, $t\left(q_{t}\right)$, and at equilibrium $(\mathrm{mg} / \mathrm{g})\left(q_{e}\right)$ respectively, 
and $k_{1}(\mathrm{l} / \mathrm{min}), k_{p}$, and $k_{2}(\mathrm{~g} / \mathrm{mg} \mathrm{min})$ are the rate constants for pseudo-first order, diffusion of intra-particles and pseudo-second order for the adsorption process respectively. The constant $\mathrm{C}$ depicts the intra-particle diffusion, which indicates the boundary layer thickness. For this works, as presented in Equations (6) and (7), Langmuir and Freundlich's isotherms were respectively considered.

$$
\begin{aligned}
& \frac{C_{e}}{q_{e}}=\frac{1}{b q_{m}}+\frac{C_{e}}{q_{m}} \\
& R_{L}=\frac{1}{1+b C_{0}} \\
& \log q_{e}=\log K_{F}+\frac{1}{n} \log C_{e}
\end{aligned}
$$

In Equation (6a), $b$ denotes Langmuir constant which is associated with the adsorptive energy $(\mathrm{L} / \mathrm{mg})$ while the maximum adsorption capacity $(\mathrm{mg} / \mathrm{g})$ is represented as $q_{m}$. The dimensionless equilibrium parameter, $\mathrm{R}_{\mathrm{L}}$ is a crucial feature of the Langmuir isotherm that indicates the type of the isotherm to be either linear $\left(R_{L}=1\right)$, favourable $\left(0<R_{L}<1\right)$, irreversible $\left(R_{L}=0\right)$, or unfavourable $\left(\mathrm{R}_{\mathrm{L}}>1\right)$, and $\mathrm{C}_{0}$ is the initial phenol concentration $\mathrm{mg} / \mathrm{L}$. From Equation (7), $K_{F}$ and $n$ are the Freundlich constants that provide information about the adsorption capacity and adsorption intensity respectively.

The thermodynamics of the adsorption process of phenol onto $\mathrm{MgO}-\mathrm{TiO}_{2}$ mixed oxide was described using adsorption isotherms. The $\Delta \mathrm{H}$ and $\Delta \mathrm{S}$ were determined from the slope and intercept of the linear form of Van't Hoff's Equation (8) by plotting $\ln K_{C}$ against $1 / 1$. The change in Gibbs free energy $\Delta \mathrm{G}$ was determined at different temperatures from equation (9).

$$
\begin{aligned}
& \ln K_{C}=\frac{\Delta S}{R}-\frac{\Delta H}{R T} \\
& \Delta G=(\Delta H-T \Delta S)
\end{aligned}
$$

In the equations, $\mathrm{R}$ is the universal gas constant, $\mathrm{T}$ is the absolute temperature in Kelvin, and $K_{C}$ is equilibrium constant which represents the ratio of adsorption capacity to the amount of adsorbate in the solution at equilibrium $\left(K_{C}=Q_{e} / C_{e}\right)$. 


\section{RESULTS AND DISCUSSION}

Fourier transform infrared spectrum of Piliostigma thonningii leaves extract was obtained (Figure not shown). In the spectrum, peak due to $\mathrm{N}-\mathrm{H}$ stretching bond or carboxylic acid $(\mathrm{COOH})$ and aliphatic hydroxyl $(\mathrm{OH})$ groups was observed at $3480 \mathrm{~cm}^{-1}$. The wavenumber 707 $\mathrm{cm}^{-1}$ is due to $\mathrm{C}-\mathrm{S}$ stretching bond, alkyl halides, or the double bond $-\mathrm{CH}=\mathrm{CH}-$. Aromatic rings, carbonyl group $(\mathrm{C}=\mathrm{O})$ vibration or ethylenic double bond $(\mathrm{C}=\mathrm{C})$ were observed at 1634 $\mathrm{cm}^{-1}$. The peak as a result of the triple bond $C \equiv C$ stretching bond at $2052 \mathrm{~cm}^{-1}$ was also evident. The presence of amine groups in the Piliostigma thonningii leaves extract as observed in the FTIR result is indicative of the suitability of the leaves extract as a reducing agent for the biosynthesis of $\mathrm{MgO}-\mathrm{TiO}_{2}$ mixed oxide. Also, the existence of diverse bioactive molecules

in the leaves extract of Piliostigma Thonningii will serve to reduce, cap/functionalize, or stabilize the mixed metal oxide nanoparticles in the course of synthesis. The amount of total phenols in the petroleum refinery process water was reported as $19.961 \mathrm{mg} / \mathrm{L}$

X-ray diffraction pattern of the prepared $\mathrm{MgO}-\mathrm{TiO}_{2}$ mixed oxide is presented in Figure 1. The XRD peaks are mainly due to rutile and anatase phases of titanium oxide (rutile: JCPDS card no. 00-021-1276) and (anatase: JCPDS card no. 00-021-1272). Peaks due to magnesium oxide were not revealed perhaps because it is relatively less crystalline compared to the anatase and rutile polymorphs of $\mathrm{TiO}_{2}$. Nonetheless, the presence of $\mathrm{MgO}$ has been supported by qualitative and quantitative EDX elemental compositions, and the high resolution scanning electron microscopy images. 


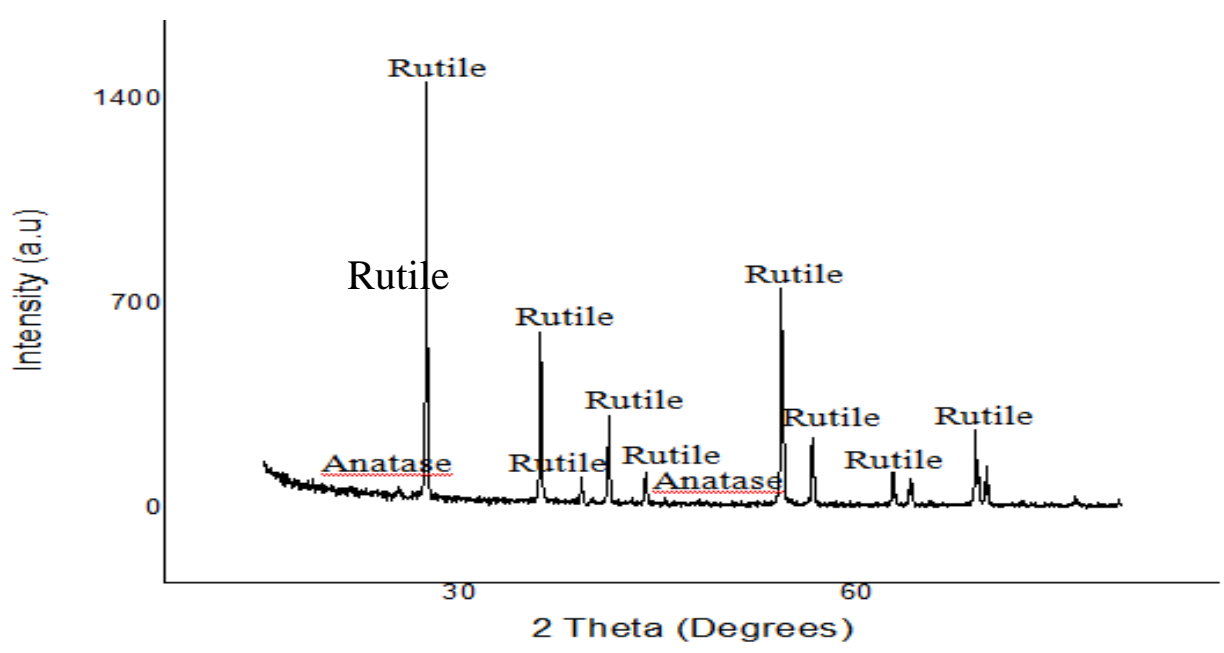

Figure 1 The XRD pattern of mixed oxide $\mathrm{MgO}-\mathrm{TiO}_{2}$

The EDX elemental analysis showed that both titanium and magnesium oxides were present in the sample as presented in Figure 2. In addition to $\mathrm{Ti}, \mathrm{Mg}$ and $\mathrm{O}$ from the mixed oxide, other elements found in the mixture are: $\mathrm{C}, \mathrm{Al}$, and $\mathrm{Si}$ which were introduced by the leaves extract used in mixed oxide preparation. It was revealed in the EDX elemental composition that the elements were present in atomic\% as $\mathrm{C}(8.23), \mathrm{O}(70.63), \mathrm{Mg}(0.87), \mathrm{Al}(1.01), \mathrm{Si}(0.65)$, and Ti(18.6). Analysis of both the XRD and EDX results imply that the formation of titanium and magnesium oxides from their corresponding nitrate salts was effective.

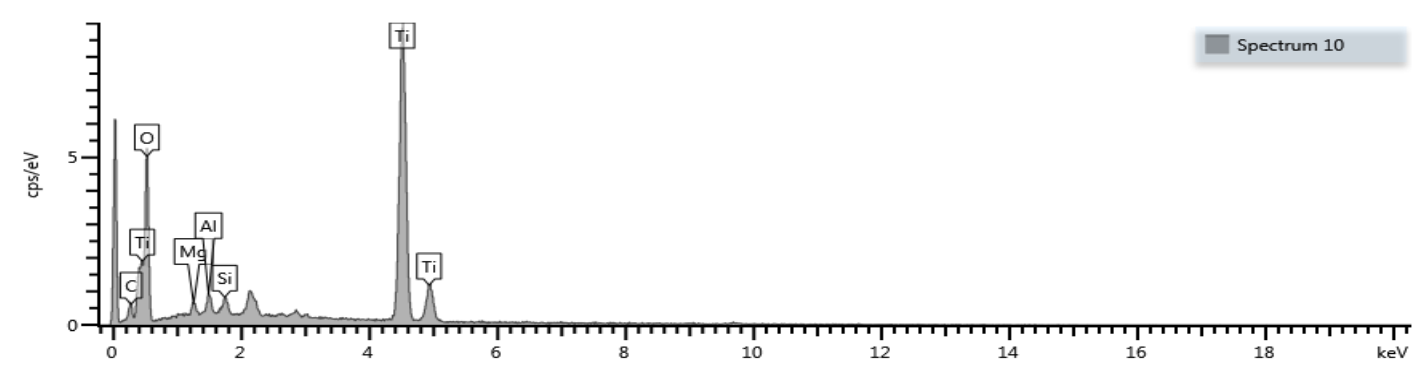

Figure 2 The EDX result of the $\mathrm{MgO}-\mathrm{TiO}_{2}$ mixed oxide

The rutile (tetrahedral, tetragonal) and anatase (octahedral) structures of the titanium oxide polymorphs present in the $\mathrm{MgO}-\mathrm{TiO}_{2}$ mixed oxide are confirmed by the HRSEM morphologies presented in Fig. 3(a) - (d). Calcination would have caused the phase transformation of the initially formed anatase into the rutile phase. Additional smaller structures appear on the surfaces of the well-defined crystalline titanium oxides and could be those of magnesium oxide. 
In Fig. 3(b), micropores can be identified in the nanoparticles, a property indicating that the mixed oxide would possess sufficient active sites for surface adsorption. The BET surface area of the synthesized $\mathrm{MgO}-\mathrm{TiO}_{2}$ nanoparticles was $215.50 \mathrm{~m}^{2} / \mathrm{g}$. A larger surface area provides more surface active sites for the adsorption of phenols from the refinery wastewater.

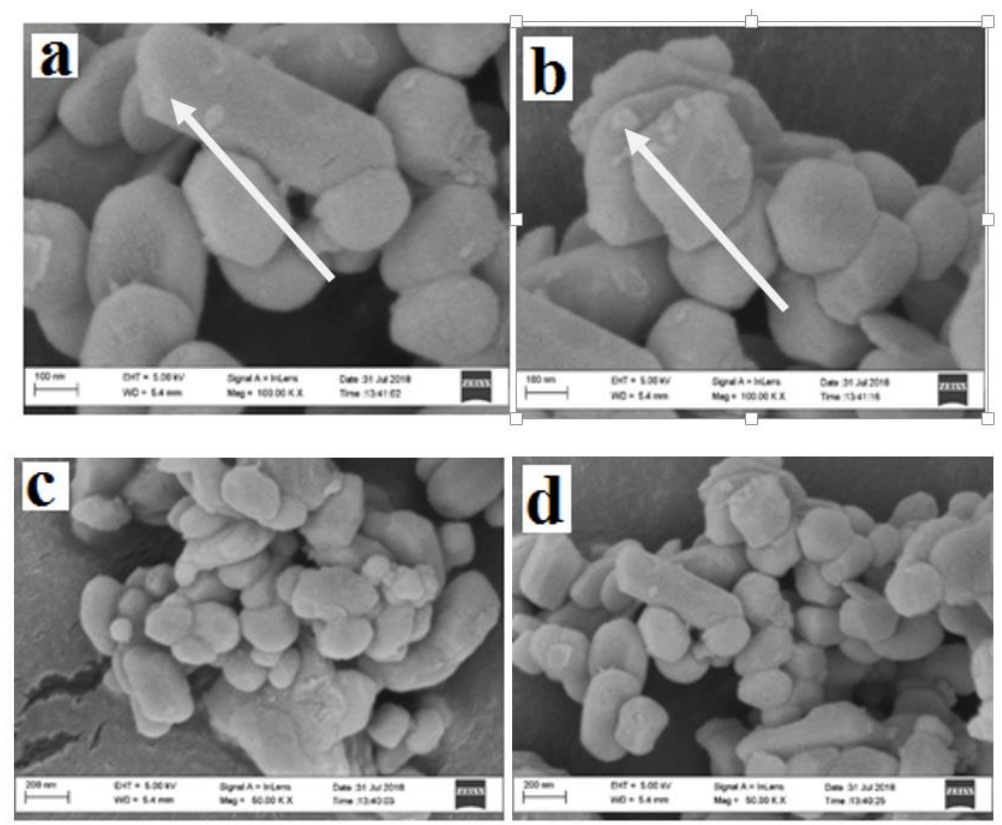

Figure 3 HRSEM Images of the $\mathrm{MgO}-\mathrm{TiO}_{2}$ mixed oxide nanoparticle (adsorbent) with rutile $\mathrm{TiO}_{2}$ indicated (a), ar. ${ }^{\text {tase }} \mathrm{TiO}_{2}$ indicated (b), and images in (a),(b) repeated at a different magnification (c),(d).

In the phenol adsorption studies using the mixed oxide, contact tine, adsorption temperature, and the adsorbent loading had notable influence towards percentage removal of phenol, as revealed in Fig. 4(a) - (c)). The optimal (most favourable) contact time was reached after 70 minutes after which the efficiency declined (Fig. 4a). The initial high rate of phenol uptake had been related to the greater vacancy on the adsorption active sites (mixed oxide surfaces). It was observed that the rate of phenol removal declined gradually after reaching the optimum at 70 minutes because most of the available sites have been occupied. It is shown in Fig. 4(b) that the percentage of phenol removal was best at $35^{\circ} \mathrm{C}$, which occurred at the optimum contact time of 70 minutes, and adsorbent dosage of $0.02 \mathrm{~g}$. Presented in Fig. 4(c) is the relationship 
between percentage phenol removal and adsorbent loading (dosage). An optimum point in percentage phenol removal was attained with $0.04 \mathrm{~g}$ of $\mathrm{MgO}^{-\mathrm{TiO}_{2}}$ mixed oxide, occurring at $35^{\circ} \mathrm{C}$ and time 70 minutes. This condition resulted in $99.5 \%$ removal of phenol. An additional dose of adsorbent resulted in a saturated aqueous mixture and could therefore block active adsorption sites, thereby causing a reduction in phenol removal due to insufficient sites.
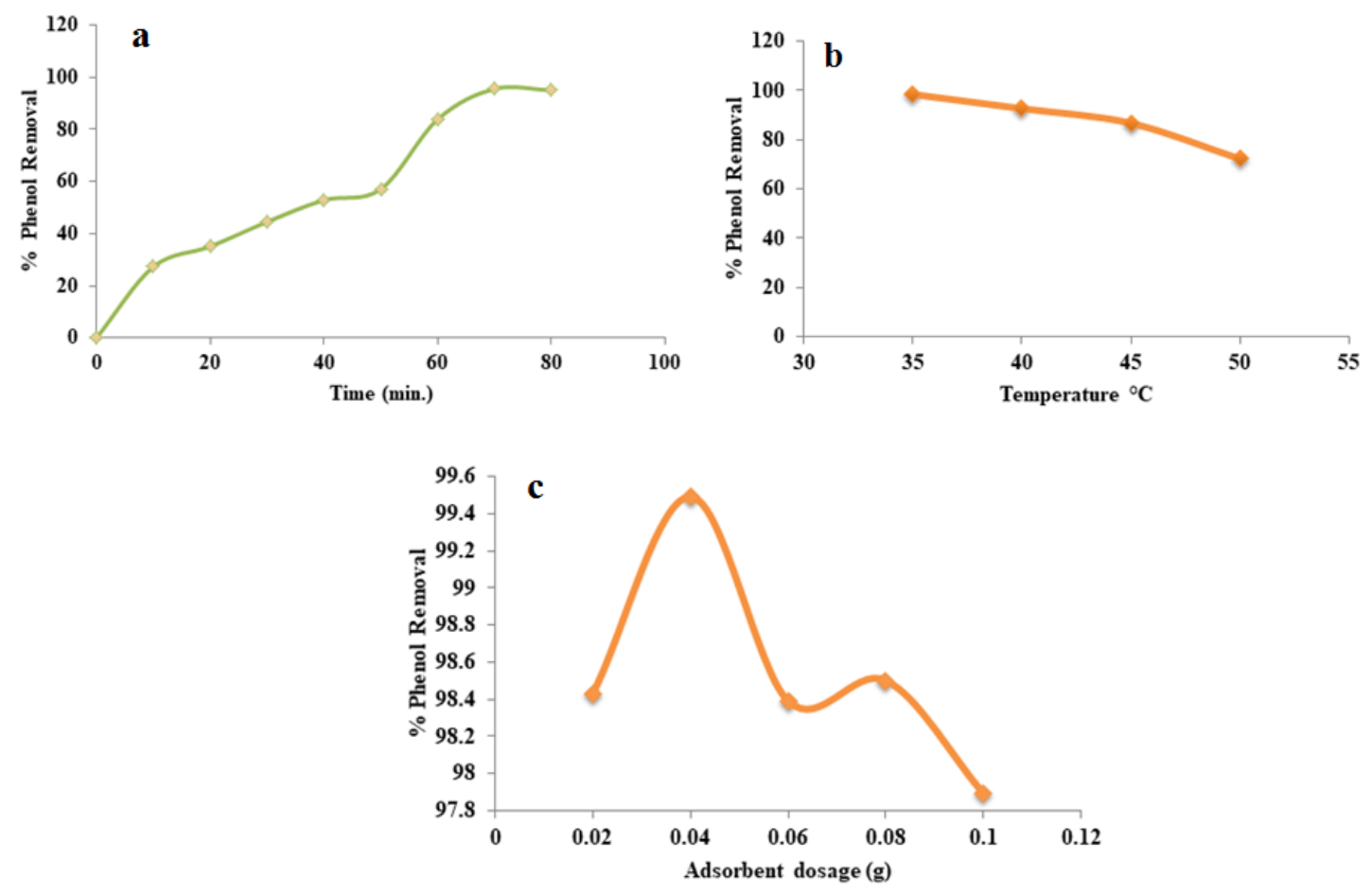

Figure 4(a) Time-dependent phenol removal by the mixed oxide (b) Temperature-dependent phenol removal by the mixed oxide (c) Adsorbent dosage-dependent phenol removal by the mixed oxide

Displayed as shown in Fig. 5(a) and (b) are the respective graphs of the kinetic models. Table 2 is a list of the pseudo-first order and pseudo-second order parameters as determined. The adsorptive phenol removal by the $\mathrm{MgO}-\mathrm{TiO}_{2}$ mixed oxide was better depicted by the model of pseudo-first order kinetic. It was found that both calculated $q_{e}$ and experimental $q_{e}$ agrees and followed the model of the pseudo-first order, and the $\left(\mathrm{R}^{2}\right)$ value was much closer to one $(1.0)$ compared to that of the pseudo-second order kinetic model. Plotting of $q_{t}$ against $\mathrm{t}^{1 / 2}$ in Fig. 5(c) showed a linear graph which is due to the intra-particle diffusion of the adsorption process. 
Such a linear graph that tends to deviate from the origin indicates that the rate-controlling step is not only controlled by the intra-particle diffusion but may also be as a result of some extent of boundary layers (Angin, 2014).
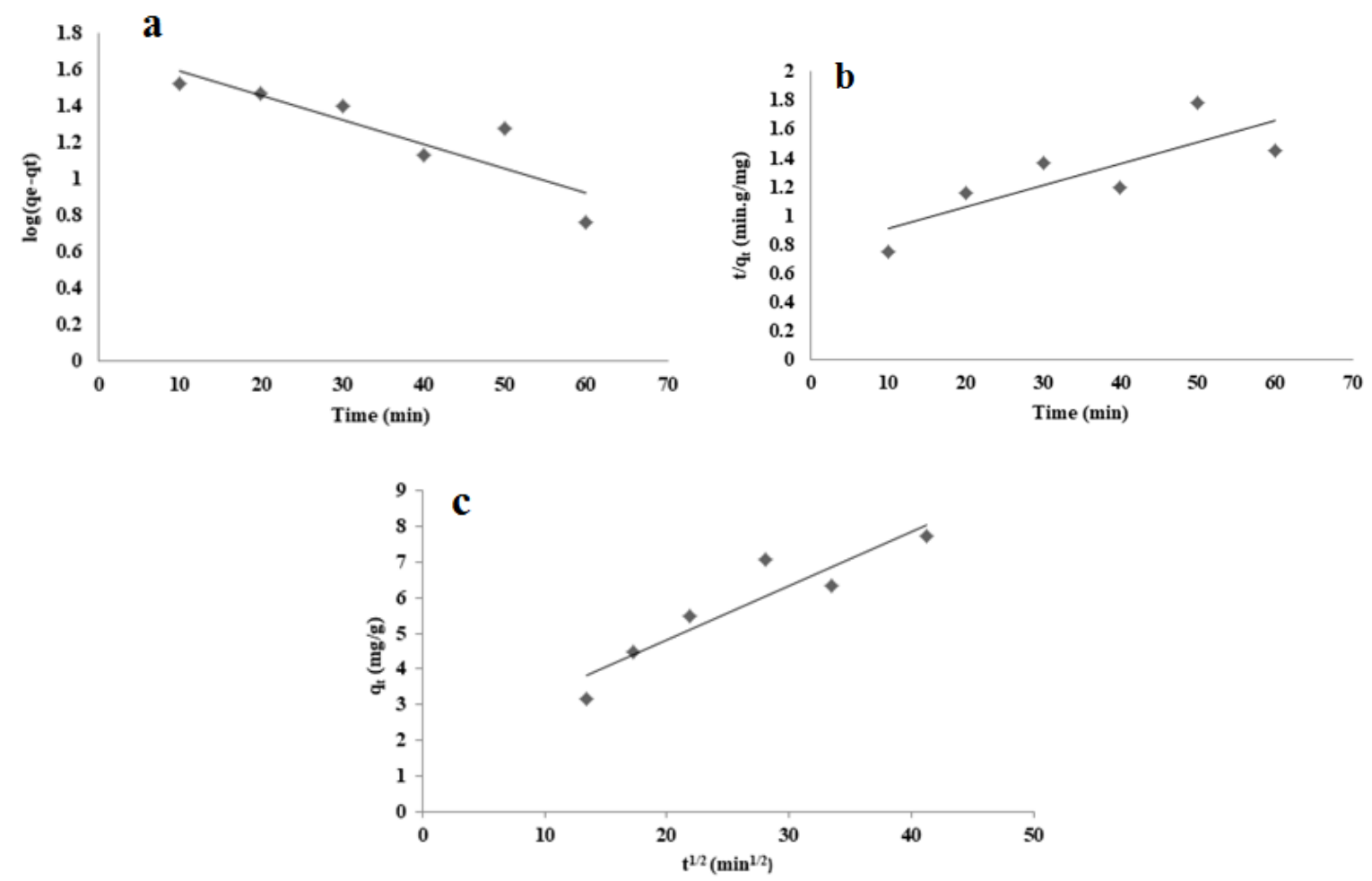

Figure 5 Fitting the phenol removal by $\mathrm{MgO}-\mathrm{TiO}_{2}$ mixed oxide to (a) pseudo-first order kinetics (b) pseudo-second order kinetics (c) intra-particle diffusion.

Table 2 Kinetics parameters for the phenol removal by the mixed oxide

particles

\begin{tabular}{cccccccccc}
\hline$R^{2}$ & $K_{1}$ & $q_{e}(\mathrm{Cal})$ & $R^{2}$ & $K_{2}$ & $q_{e}(\mathrm{Cal})$ & $R^{2}$ & $K_{P}$ & $\mathrm{C}$ & \\
& & & & & & & & & \\
& min $^{-1}$ & $m g / g$ & & g/mg.min & $\mathrm{mg} / \mathrm{g}$ & & $\mathrm{mg} / \mathrm{g} \cdot \mathrm{min}^{\frac{-1}{2}}$ & $\mathrm{mg} / \mathrm{g}$ & $\mathrm{mg} / \mathrm{g}$ \\
& & & & & & & & & \\
0.7796 & 0.03086 & 53.80 & 0.6557 & 0.000292 & 67.11 & 0.861 & 0.151 & 1.796 & 47.03
\end{tabular}


The plot in Fig. 6(a) showed that Langmuir isotherm model fitted well to the experimental data having R-squares values of 1.0 when compared to the Freundlich isotherm with an R-square value of 0.9664 . This simply means that the uptake process took place on a homogenous surface by a monolayer adsorption mechanism; all sites were occupied at once, and that the binding strength is attributed to the concentration of phenol at equilibrium. The ultimate adsorption capacity was found to be $48.077 \mathrm{mg} / \mathrm{g}$ and the $\mathrm{R}_{\mathrm{L}}$ obtained was 1.008 , indicating a linear model for the process of adsorption. The negative value of ' $n$ ' from the Freundlich isotherm plot in Fig. 6(b) suggests a chemical interface and an unfavourable adsorption route of phenol on the adsorbent. Also, the large value of $\mathrm{K}_{\mathrm{f}}$ indicates a high adsorption capacity (Vasudevan, 2014). However, the adsorption process was well fitted into the Langmuir isotherm (Fig. 6a). Table 3 shows the summary of the obtained results.
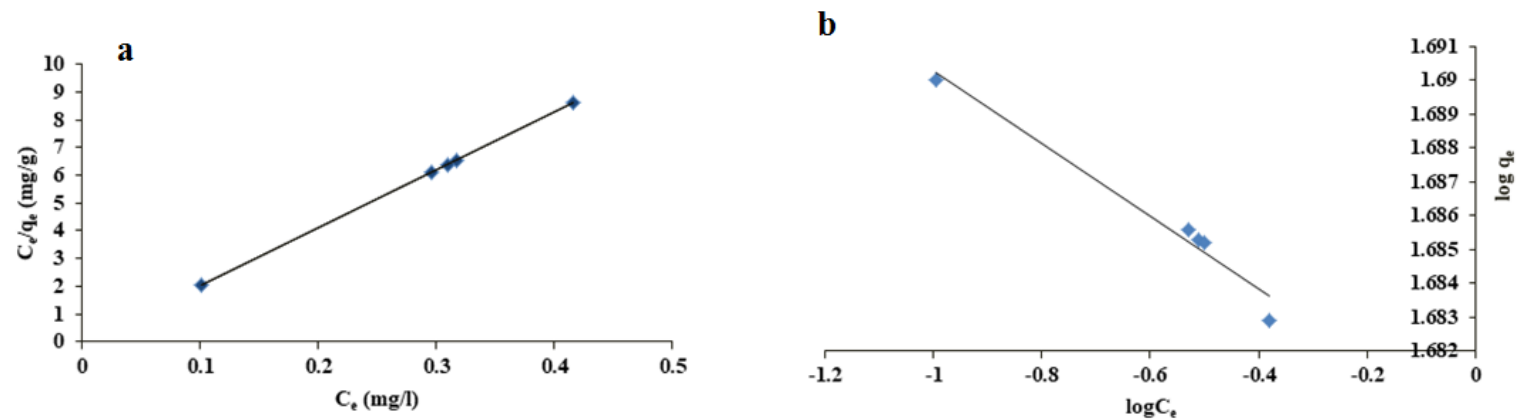

Figure 6 (a) Langmuir Isotherm for phenol adsorption onto $\mathrm{MgO}^{-\mathrm{TiO}_{2}}$ (b) Freundlich Isotherm for phenol adsorption onto $\mathrm{MgO}-\mathrm{TiO}_{2}$

Table 3 Langmuir and Freundlich constants for the adsorption of phenol onto $\mathrm{MgO}-\mathrm{TiO}_{2}$

Langmuir constants Freundlich constants

$\begin{array}{lllllll}\mathrm{R}_{\mathrm{L}} & q_{m}(\mathrm{mg} / \mathrm{g}) & \mathrm{b}(\mathrm{l} / \mathrm{mg}) & R^{2} & \mathrm{n} & K_{f}(\mathrm{mg} / \mathrm{g}) & R^{2}\end{array}$

$\begin{array}{lllllll}1.00 & 48.077 & 0.4069 & 1.0 & -93.4577 & 47.8189 & 0.9664\end{array}$


The thermodynamic plot for the phenol adsorption in refinery process wastewater using the $\mathrm{MgO}-\mathrm{TiO}_{2}$ mixed oxide is shown in Figure 7. Enthalpy was found to be $\Delta H=$ $-16.36195 \mathrm{KJ} / \mathrm{mol}$ which means that the adsorption of phenol on $\mathrm{MgO}^{-\mathrm{TiO}_{2}}$ is an exothermic reaction. The entropy $\Delta \mathrm{S}=-53.05 \mathrm{~J} / \mathrm{mol} \mathrm{K}$ suggests less randomness at the solid-solution interface and that the process of adsorption does not require much energy. The Gibb's free energy values were $-0.023 \mathrm{~kJ} / \mathrm{mol}, 0.240 \mathrm{~kJ} / \mathrm{mol}, 0.510 \mathrm{~kJ} / \mathrm{mol}$ and $0.770 \mathrm{~kJ} / \mathrm{mol}$ at temperatures $308,313,318$ and $323 \mathrm{~K}$ respectively. The negative sign of Gibb's free energy at the optimum temperature indicates spontaneous adsorption while the positive sign of Gibb's free energy above the optimum temperature indicates non-spontaneous adsorption (Djebbar et al., 2012). Values are presented in Table 4.

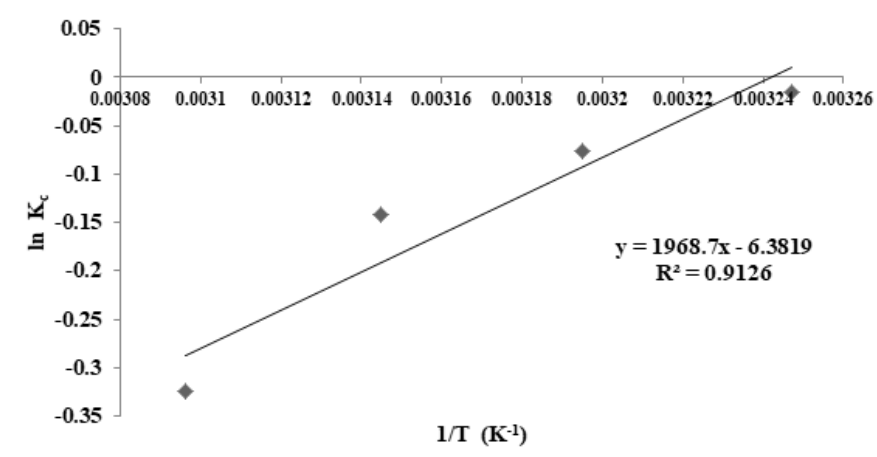

Figure 7 Thermodynamic curves for the phenol adsorption using the mixed oxide

Table 4 Thermodynamic parameters for phenol adsorption using the mixed oxide

\begin{tabular}{cccccc} 
& & $308 \mathrm{~K}$ & $313 \mathrm{~K}$ & $318 \mathrm{~K}$ & $323 \mathrm{~K}$ \\
\cline { 3 - 5 } & & - & - & - & - \\
$\Delta H(\mathrm{~kJ} / \mathrm{mol})$ & -16.36195 & - & - & - & - \\
$\Delta \mathrm{S}(\mathrm{kJ} / \mathrm{mol})$ & -0.0531 & - & & & +0.770 \\
$\Delta \mathrm{G}(\mathrm{kJ} / \mathrm{mol})$ & & -0.023 & +0.240 & +0.510 & \\
\hline
\end{tabular}

\section{CONCLUSION}

The synthesized mixed oxide nanoparticles of $\mathrm{MgO}-\mathrm{TiO}_{2}$ was found suitable for adsorptive phenol removal from refinery process wastewater. The reducing activity of the whole extract of Piliostigma thonningii on the nitrates of magnesium and titanium was illustrated towards the 
preparation of magnesium and titanium oxides. With an initial phenols concentration of 19.96 $\mathrm{mg} / \mathrm{L}$ in the raw refinery wastewater, a maximum percentage removal of $99.50 \%$ was achieved using $\mathrm{MgO}-\mathrm{TiO}_{2}$ dosage of $0.04 \mathrm{~g}$, contact time of $70 \mathrm{~min}$ and temperature of $35^{\circ} \mathrm{C}$. From the equilibrium and kinetic studies, Langmuir isotherm and pseudo-first order kinetic model defined the experimental adsorption data. It was found from the intra-particle diffusion model that the adsorption rate was not controlled only by intra-particles, but was also controlled by exterior mass transfer at the early stages of the process. It was also established that the process of adsorption was spontaneous and exothermic at the optimum temperature

\section{ACKNOWLEDGEMENTS}

The support of the Chemical Engineering Laboratory of the University of Ilorin, Ilorin Kwara state is greatly acknowledged.

\section{REFERENCES}

Angin, D. 2014. Utilization of activated carbon produced from fruit juice industry solid waste for the adsorption of Yellow 18 from aqueous solutions. Bioresource Technology. 3-7

Chen, J., Wang, J., Zhang, G., Wu, Q., \& Wang, D. 2018. Facile fabrication of nanostructured cerium-manganese binary oxide for enhanced arsenite removal from water. Chemical Engineering Journal. 334: 1518-1526.

Folin, O. \& Ciocalteu,V. J. 1927. Biological and Chemical. 73: 627-650

Gupta, A. \& Balomajumder, C. 2015. Simultaneous removal of $\mathrm{Cr}$ (VI) and phenol from binary solution using Bacillus sp. immobilized onto tea waste biomass. Journal of Water Process Engineering 6: 1-10.

Itoh, M., Hattori, H. \& Tanabe, K. 1974. The Acidic Properties of TiOs-SiOz and Its 
Catalytic Activities for the Amination of Phenol, the Hydration of Ethylene and the lsomerization of Butene. Journal of Catalysis 35: 225-231.

Jinxia, S., Akhtar, S., Zhonghua, W., Yijiang, H., Ni, H., Chunguang, R. \& Wei, Z. 2019. Adsorption removal of Congo Red from Aqueous Solution by Polyhedral $\mathrm{CuO}_{2}$ Nanoparticles: Kinetics, Isotherms. Thermodynamics and Mechanism Analysis, Journal of Alloys and Compounds. 633: 338-346.

Khan, S. U., Zaidi, R., Shaik, F., Farooqi, I. H., Azam, A., Abuhimd, H., \& Ahmed, F. 2021. Evaluation of Fe-Mg binary oxide for As (III) adsorption-synthesis, characterization and kinetic modelling. Nanomaterials. 11(3): 805.

Khoshnamvand, N., Ahmadi, S. and Mostafapour, F. K. 2017. Kinetic and Isotherm Studies on Ciprofloxacin Adsorption using Magnesium Oxide Nanoparticles. Journal of Applied Pharmaceutical Science. 7 (11): 079-083, DOI: 10.7324/JAPS.2017.71112

Mais, L., Mascia, M., Palmas, S. and Vacca, A. 2019. Separation and Purification Technology Photoelectrochemical oxidation of phenol with nanostructured $\mathrm{TiO}_{2}$-PANI electrodes under solar light irradiation. Separation and Purification Technology. 208: 153-159.

Mohamadi, S. K. A., Sanaeepur, H., Abbassian, K., Najafi, A., Mofarrah, E. 2015. Phenol Removal From Industrial Wastewaters: A Short Review, Desalin Water Treat. 53: 2215. Mustapha, S. I., Aderibigbe, F. A., Adewoye, T. L., Mohammed, I. A., \& Odey, T. O. 2021. Silver and titanium oxides for the removal of phenols from pharmaceutical wastewater. Materials Today: Proceedings. 38: 816-822.

Tasic, Z. G. V. \& Antonijevic, M.M. 2014. The Mechanism And Kinetics of Degradation Of Phenolics in Wastewaters Using Electrochemical Oxidation. International Journal of Electrochemical Science. 9: 3473-3490.

Vasudevan, S. (2014). An efficient removal of phenol from water by peroxi electrocoagulation processes. Journal of Water Process Engineering. 2: 53-57 